Supporting Information

\title{
Enabling the Low-Temperature Cycling of NMC $\mid$ Graphite Pouch Cells with an Ester-Based Electrolyte
}

\author{
Yoon-Gyo Cho ${ }^{\mathrm{a}, \dagger}$, Mingqian $\mathrm{Li}^{\mathrm{b}, \dagger}$, John Holoubek ${ }^{\mathrm{a}, \dagger}$, Weikang $\mathrm{Li}^{\mathrm{a}}$, Yijie Yin ${ }^{\mathrm{c}}$, Ying Shirley \\ Meng $^{\mathrm{a}, \mathrm{c}, \mathrm{d}}$, Zheng Chen ${ }^{\mathrm{a}, \mathrm{b}, \mathrm{c}, \mathrm{d} *}$ \\ ${ }^{a}$ Department of NanoEngineering, University of California, San Diego, La Jolla, CA 92093, USA \\ ${ }^{b}$ Program of Chemical Engineering, University of California, San Diego, La Jolla, CA 92093, \\ USA \\ 'Program of Materials Science and Engineering, University of California, San Diego, La Jolla, \\ CA 92093, USA \\ ${ }^{d}$ Sustainable Power and Energy Center, University of California, San Diego, La Jolla, CA \\ 92093, USA \\ ${ }^{\dagger}$ These authors contributed equally to this work.
}




\section{Experimental}

\section{Cell preparation}

The pouch-type full-cells were used to investigate the effects of our designed electrolyte and conventional electrolytes on battery cell performances. Cathode composition = $\mathrm{LiNi}_{1 / 3} \mathrm{Mn}_{1 / 3} \mathrm{Co}_{1 / 3} \mathrm{O}_{2} / \mathrm{PVdF}$ (Kynar® HSV 1800) / carbon black (Super-P) at $80: 10: 10$ (wt.\%); cathode areal capacity $=1.5 \mathrm{mAh} \mathrm{cm}^{-2}$, anode composition $=$ graphite $(\mathrm{GCP}-80) / \mathrm{PVdF}$ $($ Kynar® HSV 1800) / carbon black (Super-P) at $90: 5: 5$ (wt.\%); anode areal capacity $=1.7$ $\mathrm{mAh} \mathrm{cm}^{-2}$. Slurries of positive and negative electrodes were coated on aluminum and copper foils, respectively and dried overnight under vacuum at $80{ }^{\circ} \mathrm{C}$. The size of the cathode and anode was $44 \mathrm{~mm} \times 57 \mathrm{~mm}$ and $45 \mathrm{~mm} \times 58 \mathrm{~mm}$, respectively. A microporous polyethylene separator (PE) (Celgard 2400) was placed between a cathode and an anode. Our designed electrolyte of this work is $1 \mathrm{M} \mathrm{LiPF}_{6}$ in a mixture of methyl propionate (MP, 99\%; Sigma Aldrich) and fluoroethylene carbonate (FEC, >98.0\%; TCI Chemical) at $90: 10$ (vol.\%), abbreviated as M9F1. Both LP40 and LP30 were used as control electrolytes. LP40 $=1 \mathrm{M} \mathrm{LiPF}_{6}$ in EC/DEC at $50: 50$ (vol.\%) (Sigma Aldrich); LP30 = 1M LiPF 6 in EC/DMC at $50: 50$ (vol.\%) (Sigma Aldrich).

\section{Electrochemical characterization}

For the rate capability test at room temperature, the pouch cells were galvanostatically charged to $4.3 \mathrm{~V}$ and then held potentiostatically until the current reached $5 \%$ of the charge current. Subsequently, the cells were galvanostatically discharged to $2.7 \mathrm{~V}$ at different C-rates. For lowtemperature cycles, the pouch cells were galvanostatically charged to $4.3 \mathrm{~V}$ and then potentiostatically charged at the same voltage under room temperature, and then galvanostatically discharged to $2.7 \mathrm{~V}$ after switching the temperature to either $-20{ }^{\circ} \mathrm{C}$ or $-40{ }^{\circ} \mathrm{C}$. After discharge, the cells were repeatedly charged and discharged at same temperature condition 
at either $-20{ }^{\circ} \mathrm{C}$ or $-40{ }^{\circ} \mathrm{C}$. Battery testers (Neware BTS-4000 and Arbin LBT-10V5A) were used for electrochemical cycling.

The electrochemical impedance spectroscopy (EIS) was performed on pouch-type full-cells after rate capability test. The impedance spectra were obtained between $1 \mathrm{mHz}$ to $1 \mathrm{MHz}$ with an AC amplitude of $10 \mathrm{mV}$ at both room temperature and $-20^{\circ} \mathrm{C}$. For the EIS of three-electrode pouch cells, the cells were pre-cycled for 5 times and then brought to $50 \%$ state of charge (SOC). A thin and small lithium metal strip was used as a reference electrode and placed next to the cathode and the anode. The impedance spectra were obtained from $5 \mathrm{mHz}$ to $200 \mathrm{MHz}$, and from $1 \mathrm{mHz}$ to $1 \mathrm{MHz}$ for room temperature and $-20{ }^{\circ} \mathrm{C}$ operation, respectively. All impedance spectra were collected by EC-Lab, and component values were obtained by fitting the spectra with a Z-Fit module in EC-Lab. Three-electrode pouch cells subject to low temperature discharge were assembled in small pouch cells, composed of 12-mm diameter anode and cathode electrodes separated by 2 Celgard separators in between which a Li metal reference electrode was placed. These cells were charged at $\mathrm{C} / 5$ at their temperatures of interest until the graphite was fully lithiated $(0 \mathrm{~V})$ before discharge measurements. Average polarization was calculated by subtracting the room temperature voltage of each electrode from their $-20{ }^{\circ} \mathrm{C}$ voltage at equivalent capacities.

\section{Materials characterization}

The ionic conductivity of the electrolytes was measured by a customized stainless-steel twoelectrode cells, in which two polished 316 stainless-steel (SS 316) were spaced symmetrically. The cell constant for calibration was performed from 0.447 to $80 \mathrm{mS} \mathrm{cm}^{-1}$ by using OAKTON standard conductivity solution. The ionic conductivities were calculated using the following 
equation: $\sigma_{\mathrm{i}}=L /(A \times R)$, where $L$ and $A$ are the length and area of internal space between the electrodes, respectively, and $R$ is the solution resistance. The data for ionic conductivities was measured by Lab View Software, which was used to control an ESPEC BTX-475 temperature chamber and stored for 30 minutes intervals before measurement.

The freezing points of the electrolytes were measured under nitrogen atmosphere by differential scanning calorimetry (DSC) (TA instruments, Q2000). Aluminum hermetic pans were used for sampling. Samples were rapidly cooled down to $-90{ }^{\circ} \mathrm{C}$, and then heated up to 50 ${ }^{\circ} \mathrm{C}$ at $2{ }^{\circ} \mathrm{C} \min ^{-1}$.

X-ray photoelectron spectroscopy (XPS) was performed with an AXIS Supra DLD XPS by Kratos Analytical, and XPS spectra were corrected using a monochromatized Al K $\alpha$ radiation $(\lambda=0.83 \mathrm{~nm}$ and $h v=1,486.7 \mathrm{eV})$ under a base pressure at $10^{-9} \mathrm{~Pa}$. The samples were directly transferred into the XPS chamber from a nitrogen-filled glovebox to avoid the moisture and air exposure. Ar plasma of $5 \mathrm{keV}$ was used for etching the electrode surface with a pre-etching for 5 s, etching for $120 \mathrm{~s}$. Morphologies on the electrodes were examined by a scanning electron microscopy (SEM) on a Bruker X8-ApexII CCD diffractometer equipped with Mo K $\alpha$ radiation at $50 \mathrm{kV}$ and $50 \mathrm{~mA}$. Before investigating, all electrode samples were carefully washed by dimethyl carbonate (DMC) to remove the residual electrolyte solvents and salts from the electrodes, which was conducted in an Ar-filled glovebox (Mbraun; $<0.1 \mathrm{ppm}_{2}$ and $\mathrm{H}_{2} \mathrm{O}$ ).

\section{Cell gassing test}

Cell gassing test was performed through three-layer pouch-type full cells (cell capacity $~ 120$ $\mathrm{mAh})$ and the gas volume was measured using the Arrhenius method according to Dahn et al ${ }^{1}$. Cells were weighed while submerged in deionized water $(18 \mathrm{M} \Omega \mathrm{cm})$ before and after the 
experiment. The difference in weight of the pouch cell while submerged in water is then directly proportional to the volume of gas produced. The volume of the gas generated after cycling is then calculated by the following equation:

$$
\begin{aligned}
& \text { Density of the cell }=\frac{\text { Weight in air }}{\text { Weight in air-Weight in water }} \times \text { Density of water } \\
& \text { Volume of gas generation }=\frac{\text { Weight of the cell }}{\text { density before cycling }}-\frac{\text { Weight of the cell }}{\text { density after cycling }}(2)
\end{aligned}
$$


Table S1. Physical properties of organic solvents.

\begin{tabular}{c|c|c|c|c}
\hline $\mathbf{C o d e}^{\mathbf{a}}$ & $\mathbf{T}_{\mathbf{f}} /{ }^{\mathbf{o}} \mathbf{C}$ & $\mathbf{T}_{\mathbf{b}} /{ }^{\mathbf{o}} \mathbf{C}$ & $\eta_{\mathbf{R T}} / \mathbf{c P}$ & $\boldsymbol{\varepsilon}_{\mathbf{R T}}$ \\
\hline EC & 36.4 & 248 & $1.93^{\mathrm{b}}$ & $89.78^{\mathrm{b}}$ \\
DMC & 4.6 & 91 & 0.59 & 3.107 \\
DEC & -74.3 & 126 & 0.75 & 2.8 \\
FEC & 20 & 212 & 3.98 & 109 \\
MP & -87.5 & 88 & 0.43 & 6.20 \\
\hline
\end{tabular}

$\overline{\mathrm{T}_{f} \text { and } \mathrm{T}_{b}=\text { freezing and boiling temperature, respectively. } \eta_{\mathrm{RT}}=\text { viscosity at R.T., } \varepsilon_{\mathrm{RT}}=}$ dielectric constant at R.T., R.T. = room-temperature.

${ }^{\mathrm{a}} \mathrm{EC}=$ ethylene carbonate, $\mathrm{DMC}=$ dimethyl carbonate, $\mathrm{DEC}=$ diethyl carbonate, $\mathrm{FEC}=$ fluoroethylene carbonate, MP = methyl propionate.

${ }^{\mathrm{b}}$ Measured at $40{ }^{\circ} \mathrm{C}$. 
Table S2. Summary of ionic conductivities.

\begin{tabular}{ccccc}
\hline Temp. $\left({ }^{\circ} \mathbf{C}\right)$ & $\begin{array}{c}\mathbf{L P 4 0} \\
\left(\mathbf{m S ~ c m} \mathbf{~ c m}^{-1}\right)\end{array}$ & $\begin{array}{c}\mathbf{L P 3 0} \\
\left(\mathbf{m S ~ c m} \mathbf{~ c m}^{-1}\right)\end{array}$ & $\begin{array}{c}\mathbf{M 9 F 1} \\
\left(\mathbf{m S ~ c m} \mathbf{~ c m}^{-1}\right)\end{array}$ \\
\hline 30 & 8.15 & 12.13 & 12.51 \\
10 & 6.94 & 10.56 & 12.04 \\
0 & 5.57 & 8.90 & 11.43 \\
-10 & 2.06 & 6.87 & 10.36 \\
-20 & 1.23 & 5.19 & 8.95 \\
-30 & 0.74 & 3.48 & 7.66 \\
-40 & 0.28 & 0.24 & 6.18 \\
-50 & 0.11 & 0.04 & 4.86 \\
-60 & 0.03 & 0.01 & 3.53 \\
\hline
\end{tabular}


(a) at $25^{\circ} \mathrm{C}$

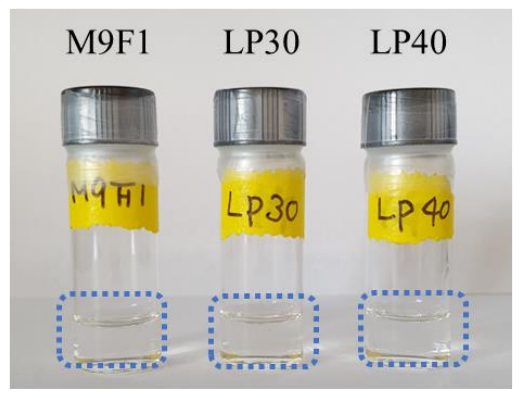

(b) at $-40^{\circ} \mathrm{C}$

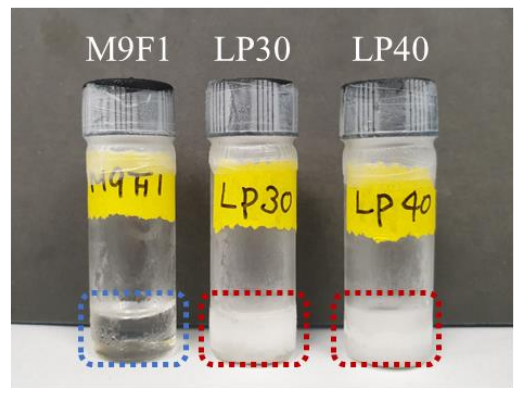

(c) at $-60^{\circ} \mathrm{C}$

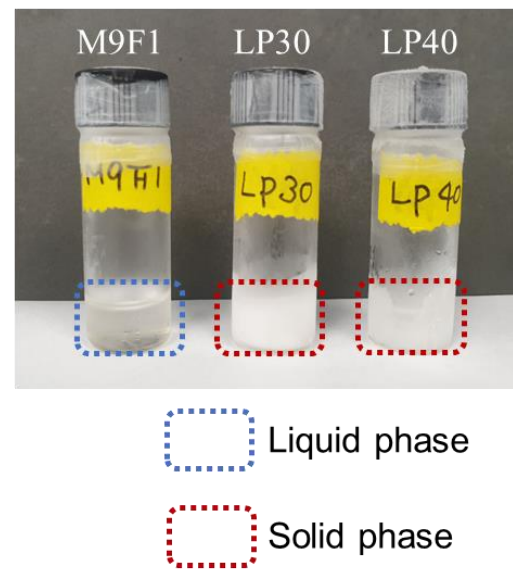

Figure S1. Optical images of different electrolytes after storage for 12 hours at different temperatures. $1 \mathrm{~mL}$ of electrolyte solution was added in each glass vial. $\mathrm{M} 9 \mathrm{~F} 1=1 \mathrm{M} \mathrm{LiPF}_{6}$ in a mixture of MP and FEC $(9: 1 \mathrm{v} / \mathrm{v}) ; \mathrm{LP} 30=1 \mathrm{M} \mathrm{LiPF}_{6}$ in a mixture of EC and DMC $(5: 5 \mathrm{v} / \mathrm{v})$; $\mathrm{LP} 40=1 \mathrm{M} \mathrm{LiPF}_{6}$ in a mixture of EC and DEC $(5: 5 \mathrm{v} / \mathrm{v})$. 
(a)

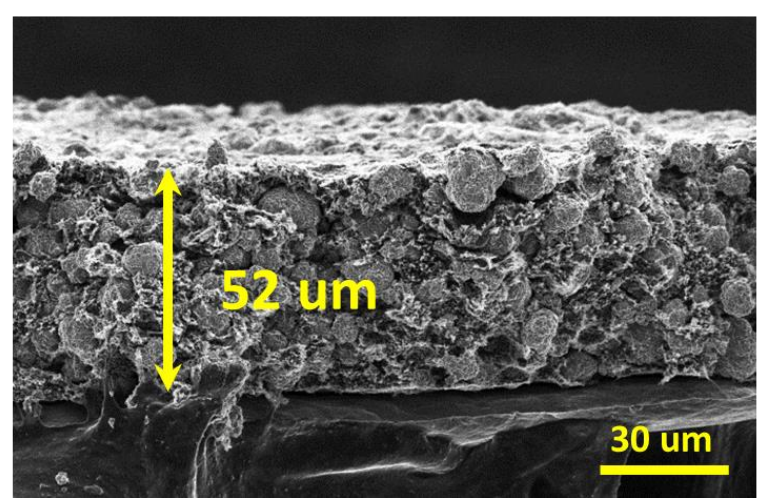

(b)

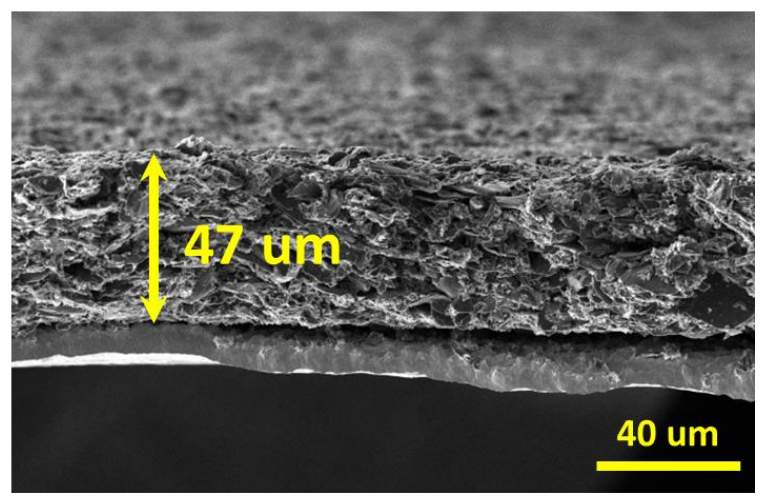

Figure S2. Cross-sectional SEM image of (a) NMC111 cathode and (b) graphite anode for pouch-type full cells. The areal capacity was designed to be $1.5 \mathrm{mAh} \mathrm{cm}^{-2}$ for cathodes and 1.7 $\mathrm{mAh} \mathrm{cm}^{-2}$ for anodes, respectively. 
(a) Pouch cell

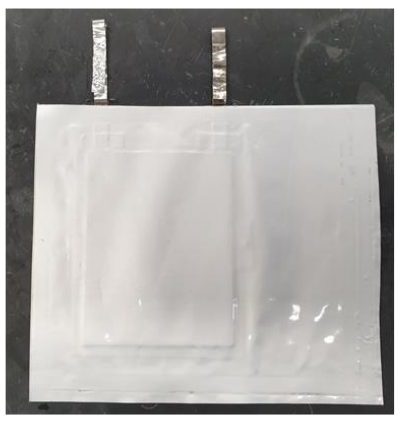

(b) Electrode design
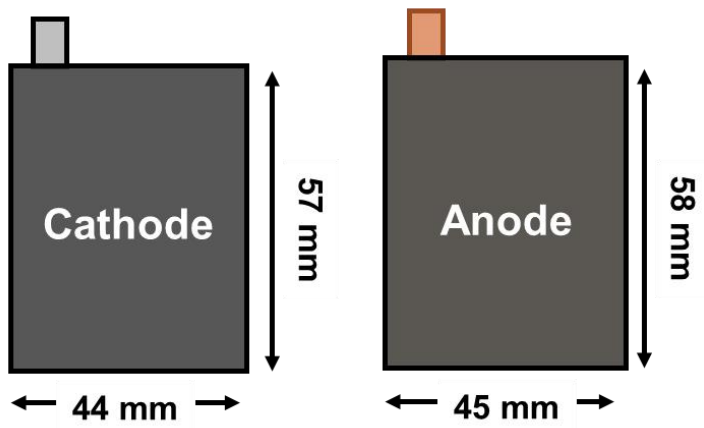

(d) SEI layer peak at $1^{\text {st }}$ charge

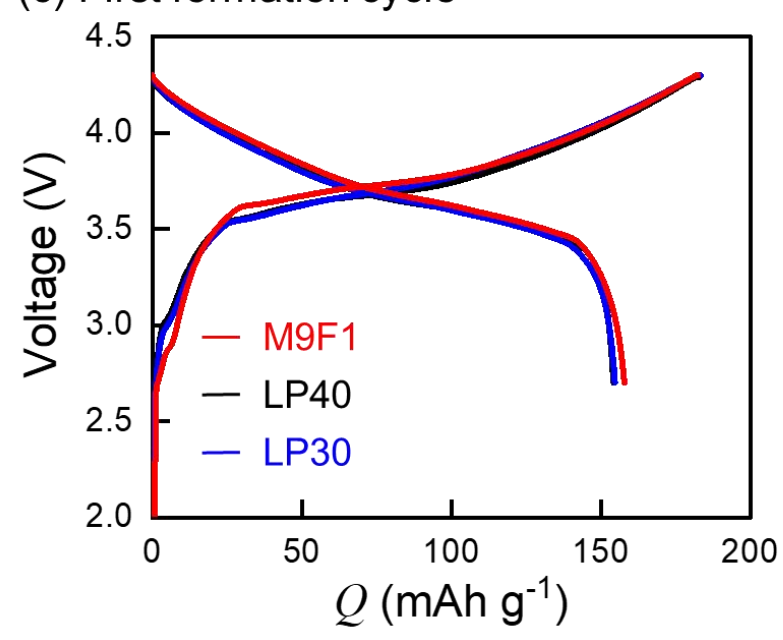

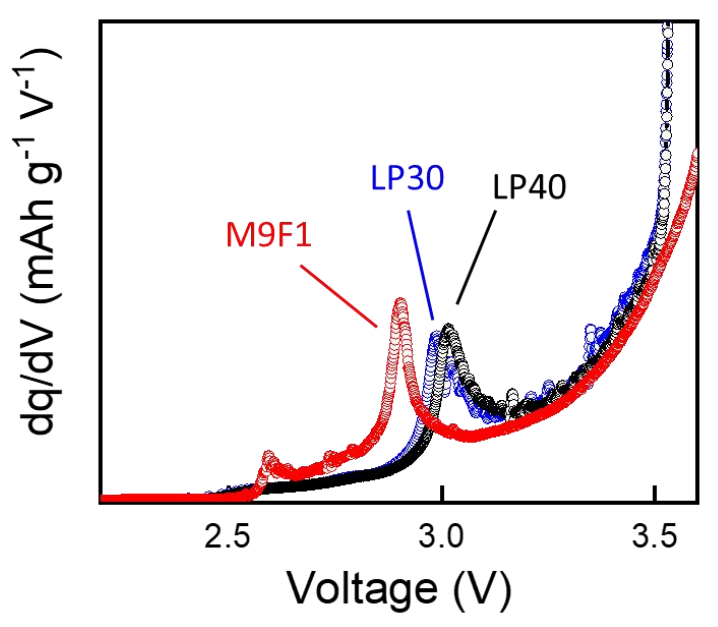

Figure S3. (a) The optical image of the assembled pouch cell containing a designed cathode and an anode (b). (c) Initial formation cycle of the pouch cells using M9F1, LP40, and LP30. (d) $\mathrm{dq} / \mathrm{dv}$ profile responsible for SEI formation peak at $1^{\text {st }}$ charge cycle shown in (c). 
(a) $\mathrm{V}$ profile of M9F1
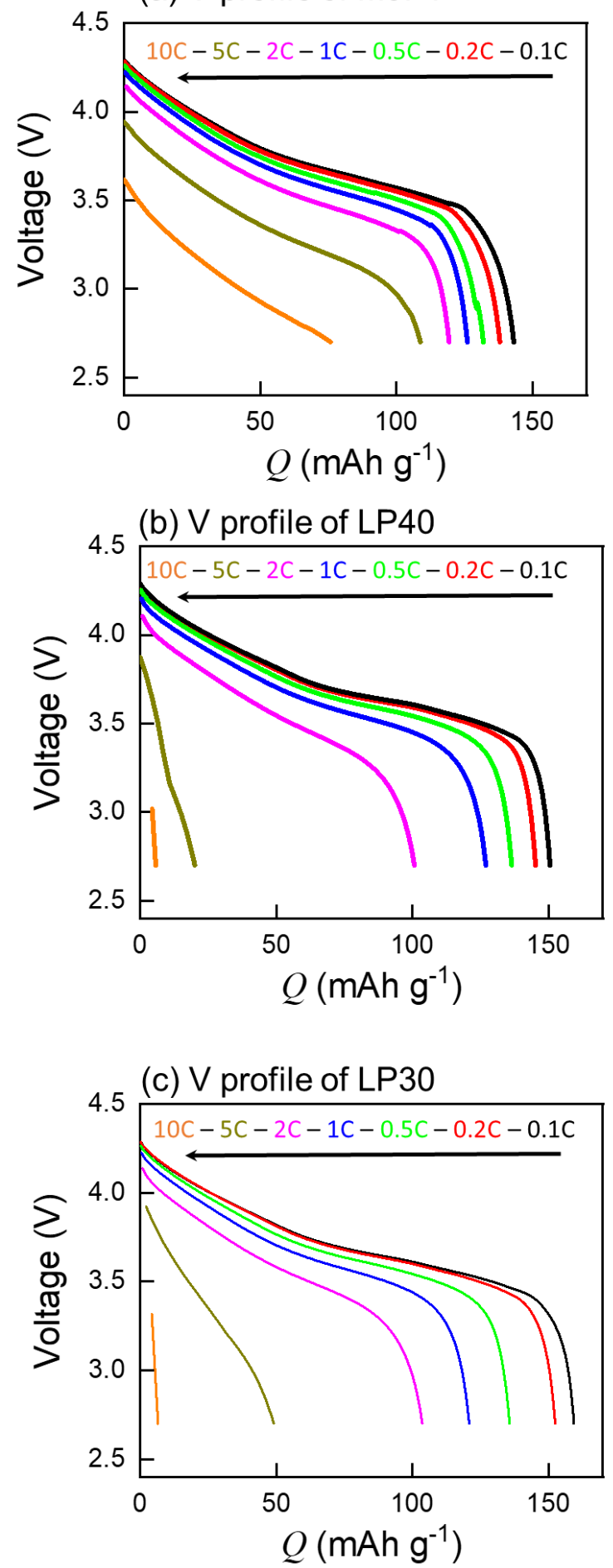

Figure S4. Voltage profiles of rate capability test for cells shown in Figure 2a. (a) M9F1, (b) LP40, (c) LP30. 
(a) Equivalent circuit
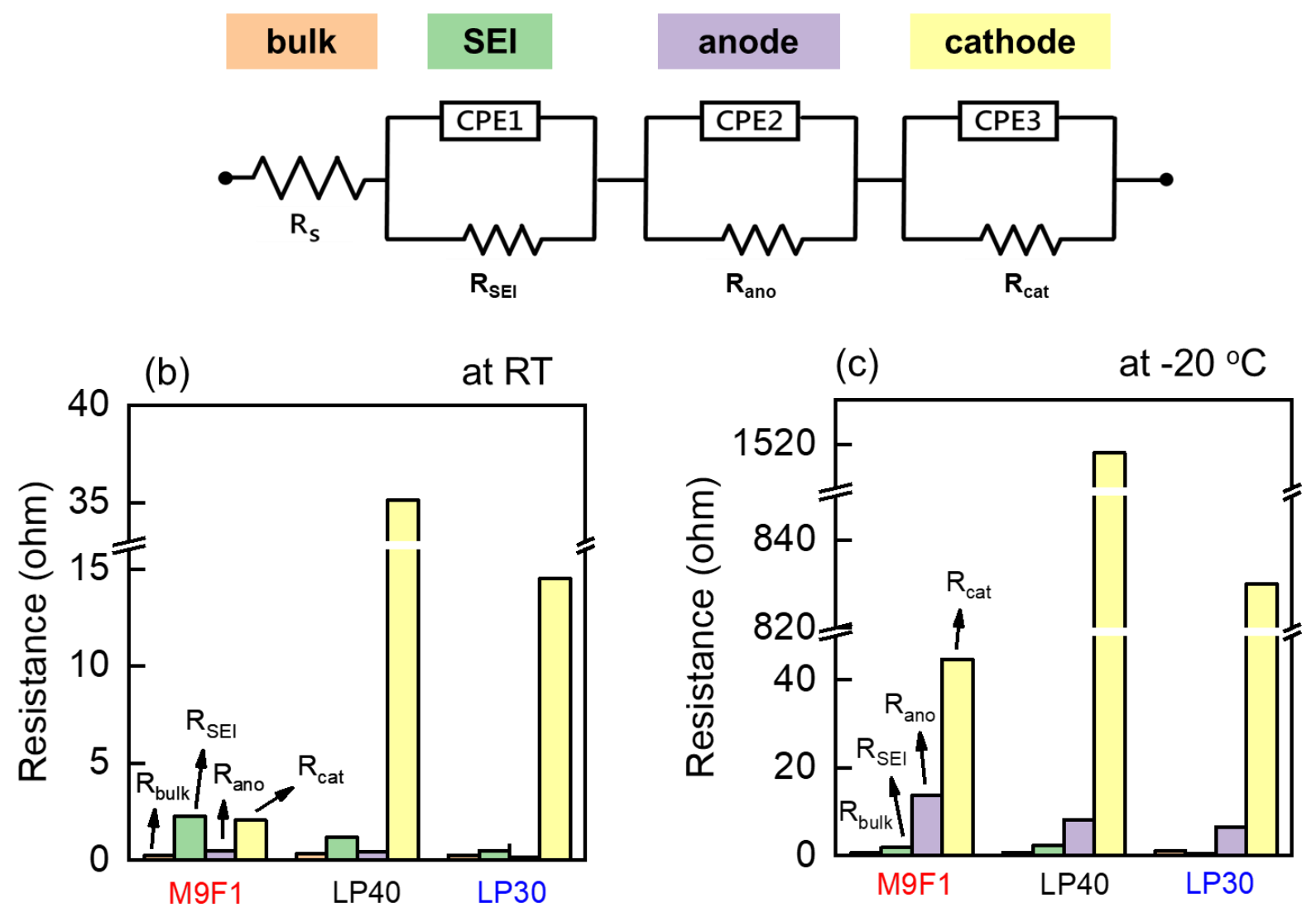

Figure S5. (a) The equivalent circuit used for interpreting the EIS spectra in Figure $2 c$ and d: $R_{s}$ $=$ bulk resistance, $\mathrm{R}_{\mathrm{SEI}}=\mathrm{SEI}$ layer resistance, $\mathrm{R}_{\mathrm{ano}}=$ anode resistance, $\mathrm{R}_{\mathrm{cat}}=$ cathode resistance, $\mathrm{C}_{\mathrm{PE} 1}=$ constant phase element representing capacitance on the interface between electrolyte and SEI layer, CPE2 = constant phase element representing capacitance on the interface between SEI layer and graphite, CPE3 = constant phase element representing capacitance on the interface between SEI layer and NMC111. (b and c) The component values obtained by fitting the spectra in Figure 2c and d. 


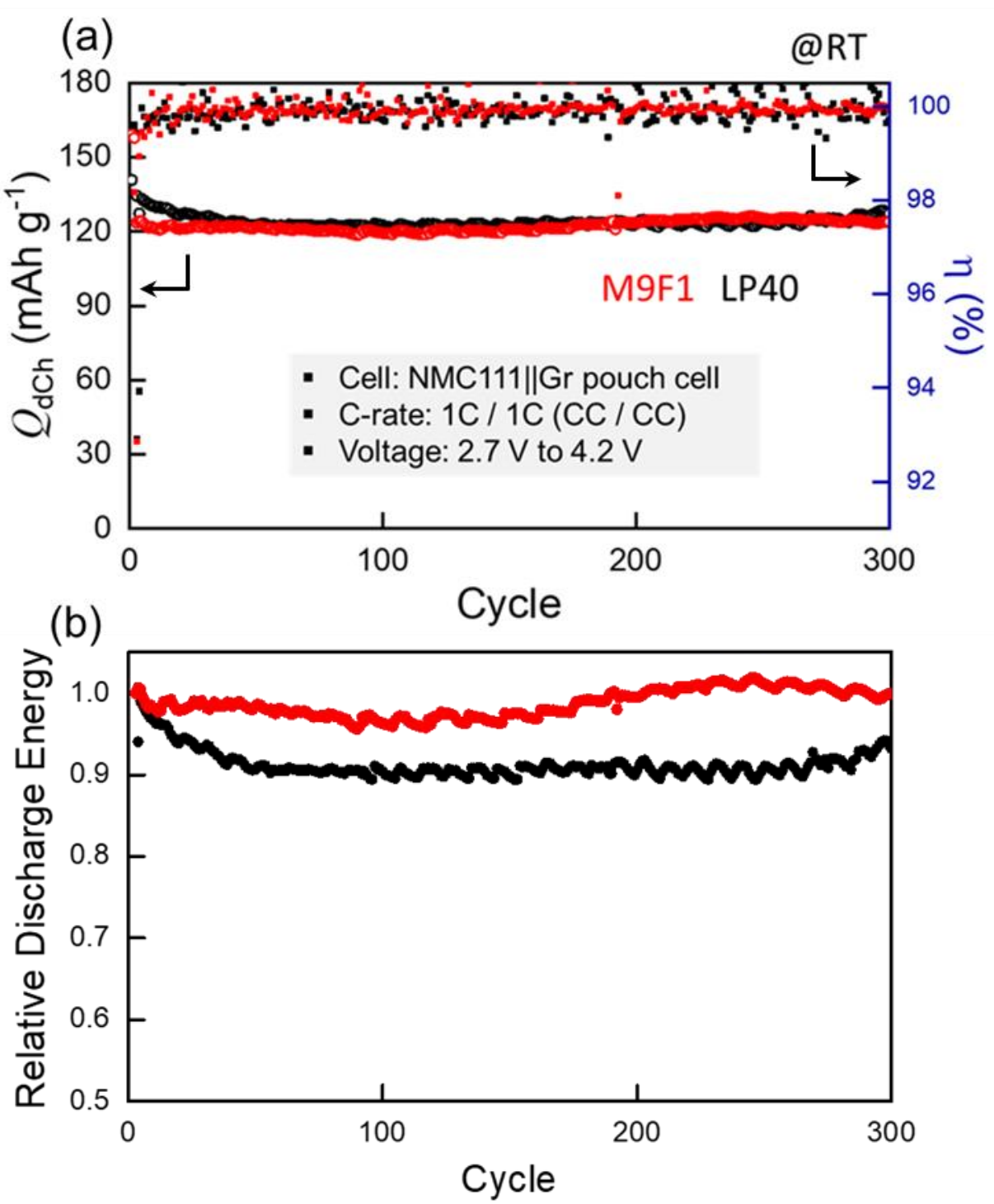

Figure S6. Room temperature cycling of NMC $111 \|$ Graphite pouch cells at a $1 \mathrm{C}$ rate. a) Capacity vs. cycle. b) Relative energy retention. The capacity fluctuation is likely due to the temperature variation during the cycling. 
(a)

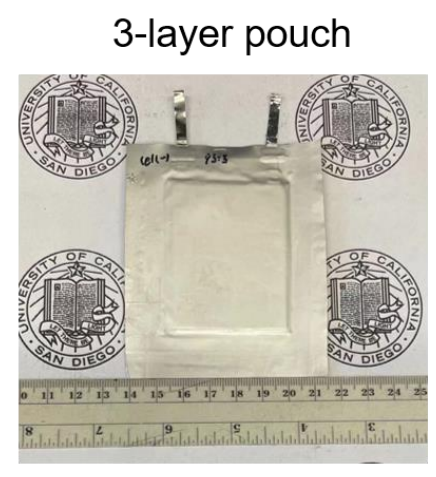

(b)

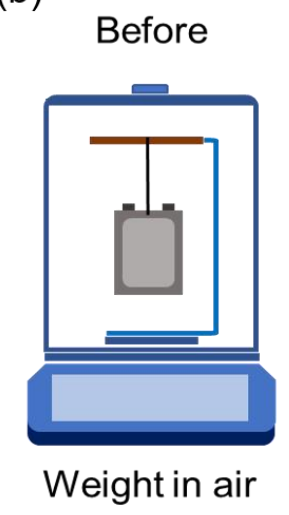

(c)

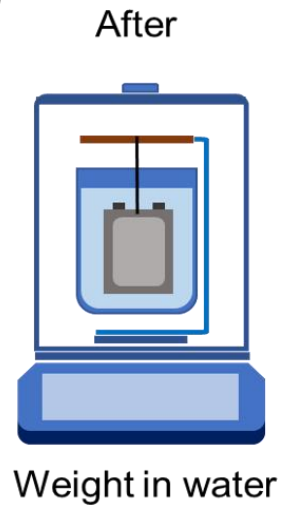

Figure S7. Gassing investigation of three-layer NMC 111 || Graphite pouch cells employing various electrolytes. 
Table S3. Gassing measurement of pouch cells with different electrolytes after 8 cycles at $0.1 \mathrm{C}$.

\begin{tabular}{c|c|c|c|}
\hline Weight (g) & LP30 & M9F1 & M95F5 \\
\hline In air & 6.7758 & & \\
\hline
\end{tabular}

In water

$\begin{array}{cccc}\text { (before cycling) } & 2.9801 & 2.8806 & 2.9733 \\ \text { In water } & & & \\ \left(\text { after } 8^{\text {th }} \text { cycle) }\right. & 2.8272 & 2.8386 & 2.780 \\ \text { Gas generation } & 0.1532 & 0.042 & \\ \text { volume }(\mathrm{ml}) & & & \\ \end{array}$




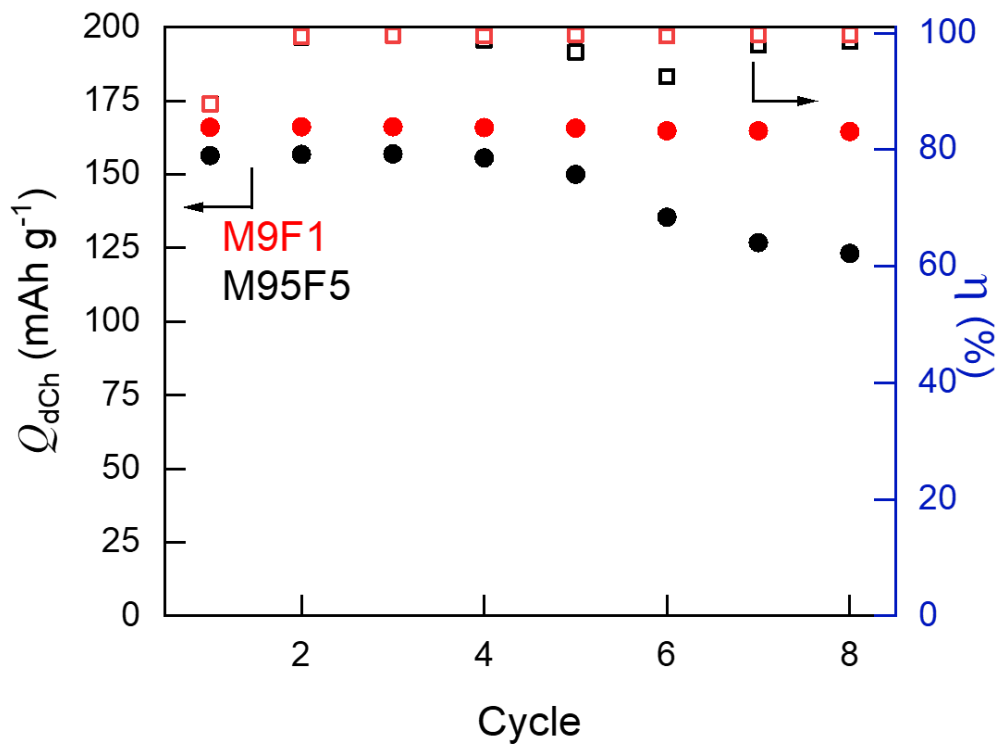

Figure S8. Cycling stability of 3-layer pouch cells using M9F1 and M95F5 electrolyte at 0.1C rate. 
(a) MF91

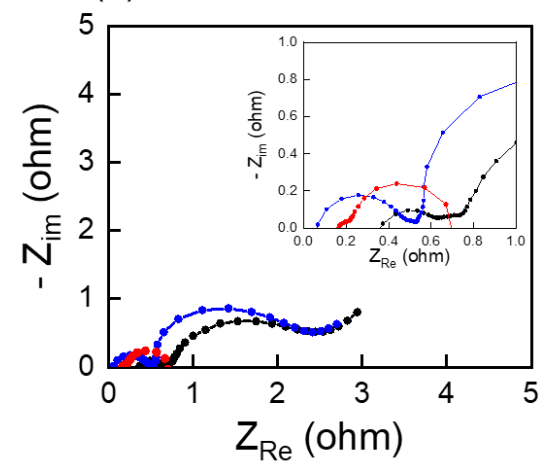

(b) LP40

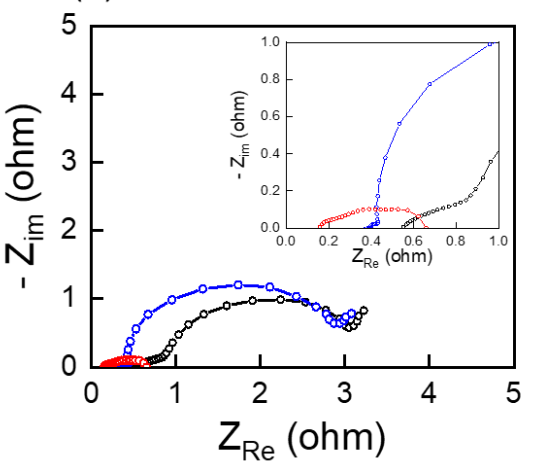

(c) LP30

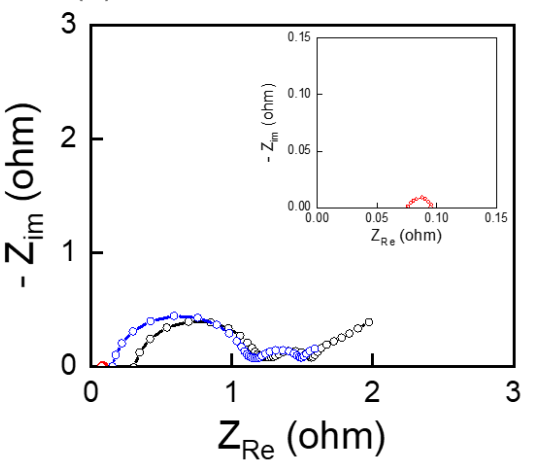

Figure S9. The impedance spectra from the three-electrode pouch cells system at roomtemperature. (a) Nyquist impedance plots of the cells using (a) M9F1, (b) LP40, and (c) LP30. Impedance of the cells were measured at 50\% SOC. Impedance spectra scanned between $5 \mathrm{mHz}$ to $200 \mathrm{kHz}$. (black: full cell; red: anode; blue: cathode). 
Table S4. Fitting values for the impedance spectra for 3-electrode pouch cells.

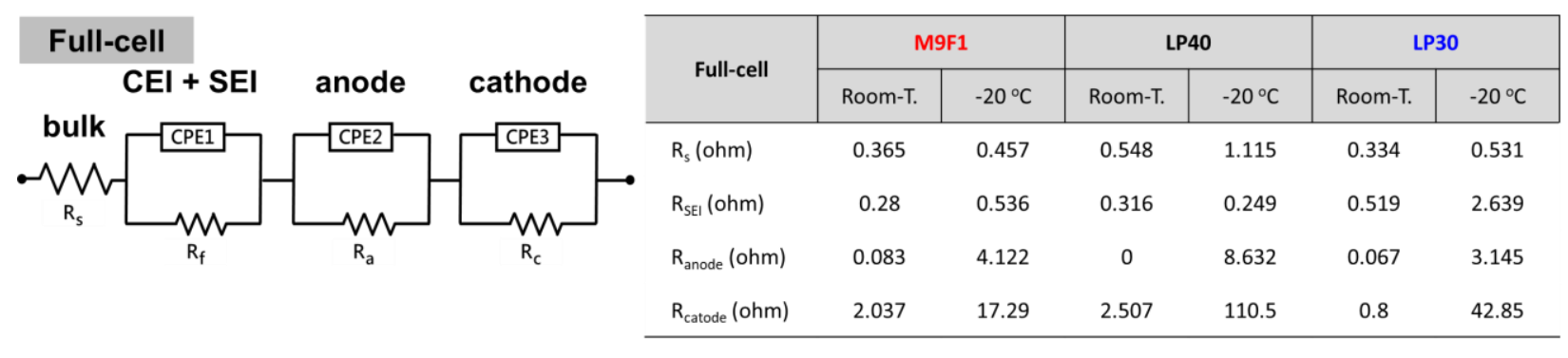

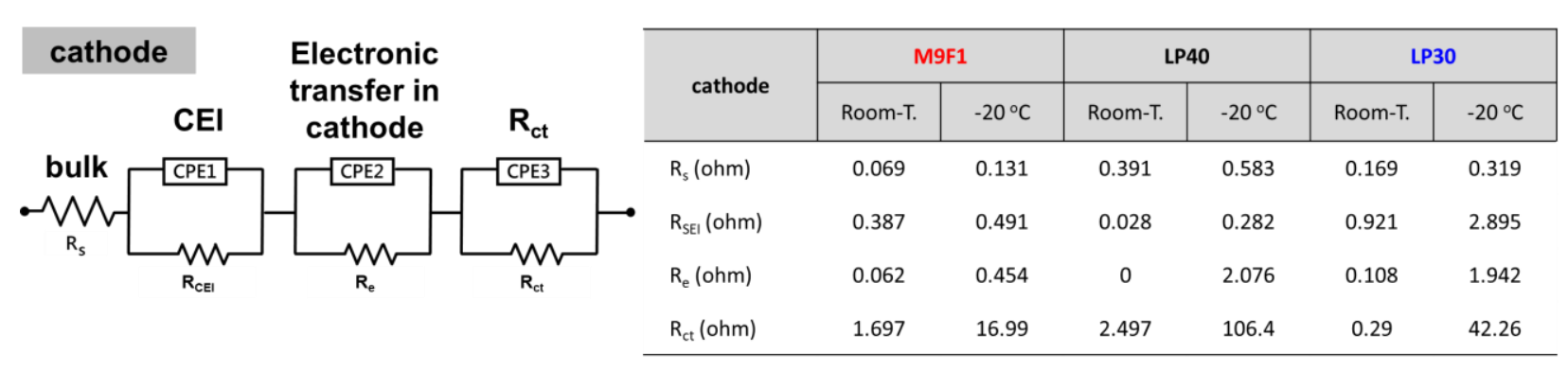

\begin{tabular}{|c|c|c|c|c|c|c|c|c|c|}
\hline anode & SEI & $\mathbf{R}_{\mathrm{ct}}$ & \multirow{2}{*}{ anode } & \multicolumn{2}{|c|}{ M9F1 } & \multicolumn{2}{|c|}{ LP40 } & \multicolumn{2}{|c|}{ LP30 } \\
\hline & \begin{tabular}{|l} 
CPE1 \\
\end{tabular} & \begin{tabular}{|l|}
\multicolumn{1}{cc}{ ct } \\
\end{tabular} & & Room-T. & $-20^{\circ} \mathrm{C}$ & Room-T. & $-20^{\circ} \mathrm{C}$ & Room-T. & $-20^{\circ} \mathrm{C}$ \\
\hline & & & $\mathrm{R}_{\mathrm{s}}$ (ohm) & 0.199 & 0.341 & 0.156 & 0.391 & 0.077 & 0.093 \\
\hline & $\mathrm{R}_{\text {SEI }}$ & $R_{\text {st }}$ & $\mathrm{R}_{\mathrm{SEl}}$ (ohm) & 0.073 & 0.063 & 0.051 & 0.121 & 0.051 & 0.032 \\
\hline & & & $\mathrm{R}_{\mathrm{ct}}(\mathrm{ohm})$ & 0.413 & 7.697 & 0.469 & 22.105 & 0.018 & 1.686 \\
\hline
\end{tabular}


(c)

(a)

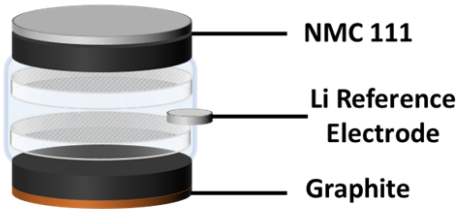

(b)

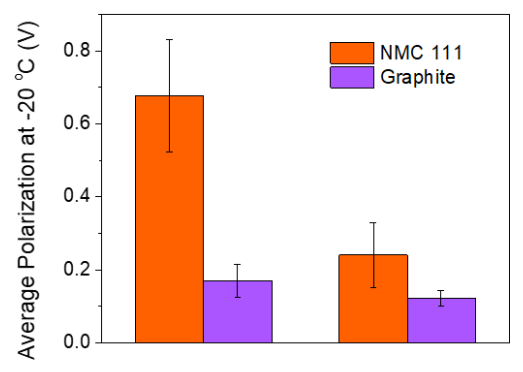

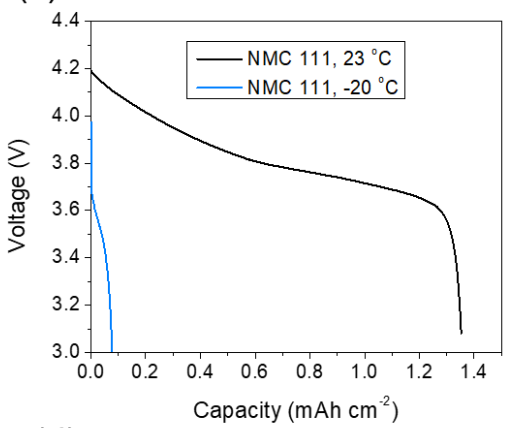

(d)

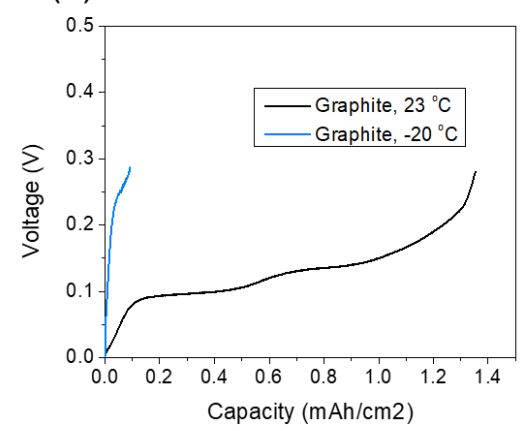

(e)

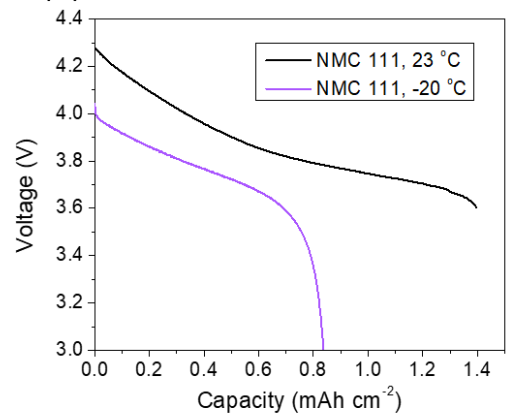

(f)

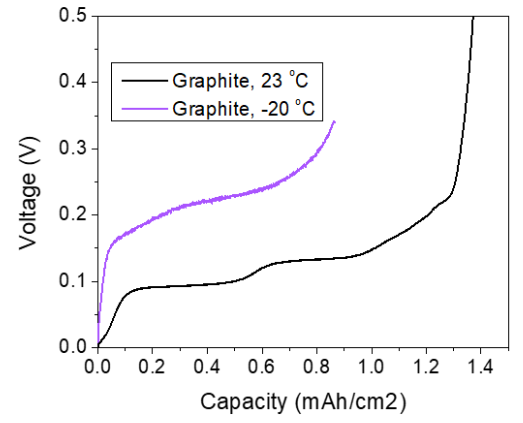

Figure S10. Three-electrode discharge profiles at room and reduced temperature. a) Schematic of three electrode cells. b) Average cathode and anode polarization between room temperature and $-20{ }^{\circ} \mathrm{C}$ calculated from voltage profiles, the error bars represent the standard deviation. c) Cathode and d) anode discharge profiles at room temperature and $-20{ }^{\circ} \mathrm{C}$ in $\mathrm{LP} 30$ at $\mathrm{C} / 5$ rate. e) Cathode and f) anode discharge profiles at room temperature and $-20{ }^{\circ} \mathrm{C}$ in $\mathrm{M} 9 \mathrm{~F} 1$ at $\mathrm{C} / 5$ rate. All investigated cells were first charged at $\mathrm{C} / 5$ in their temperature of interest at a $0 \mathrm{~V}$ cut-off for graphite. 
(a) $01 \mathrm{~s}$

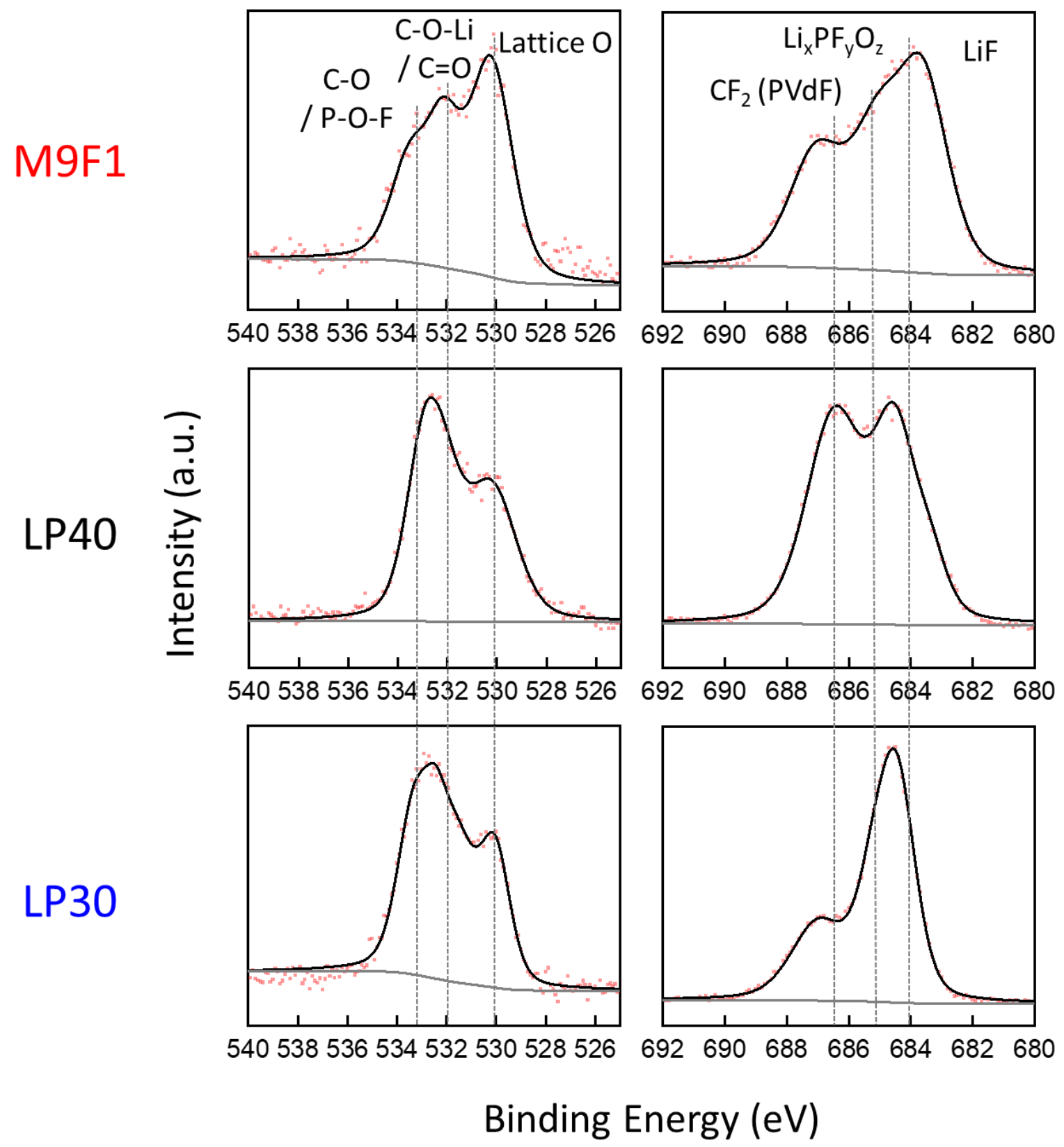

Figure S11. Characterization of electrode surfaces by XPS. a) O 1s, b) F 1s regions on NMC111 cathode surfaces. The XPS spectra were extracted after etching for 120s. 
(a)

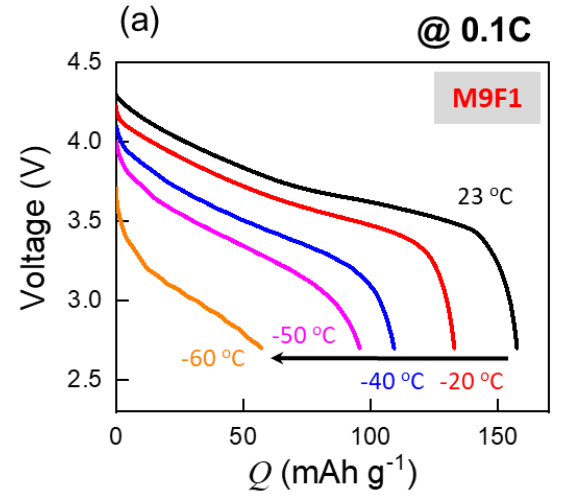

(b)

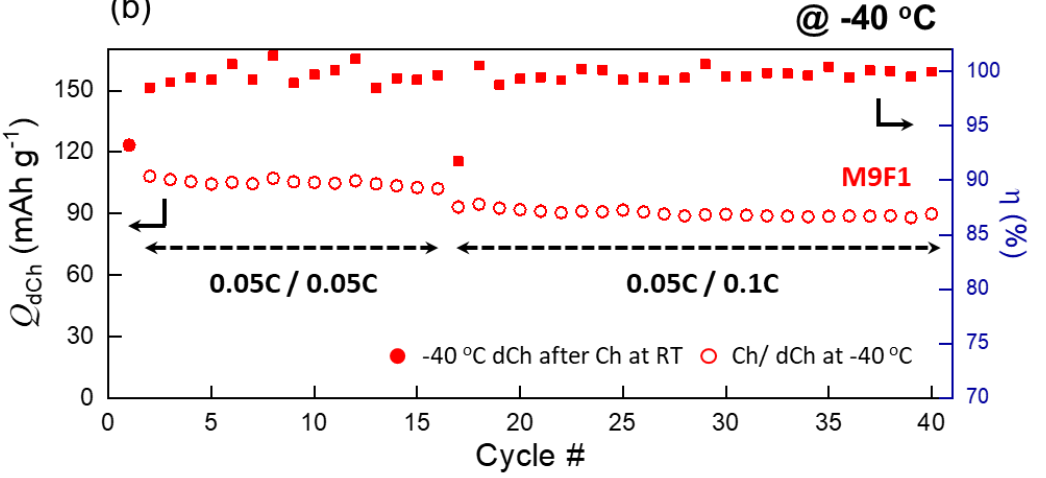

Figure S12. (a) Discharge voltage profiles of a pouch cell containing M9F1 at different temperatures. The cell was charged at room temperature before discharging at each temperature. (b) Low-temperature cycling of the cell containing M9F1 at $0.05 \mathrm{C} / 0.05 \mathrm{C}$ for 15 cycles and then $0.05 \mathrm{C} / 0.1 \mathrm{C}$ for charge and discharge, respectively. The first closed circle indicates the first discharge capacity after charge at room temperature. Following open circles indicate the repeated charge and discharge cycling after discharge at the same temperature of $-40{ }^{\circ} \mathrm{C}$. 


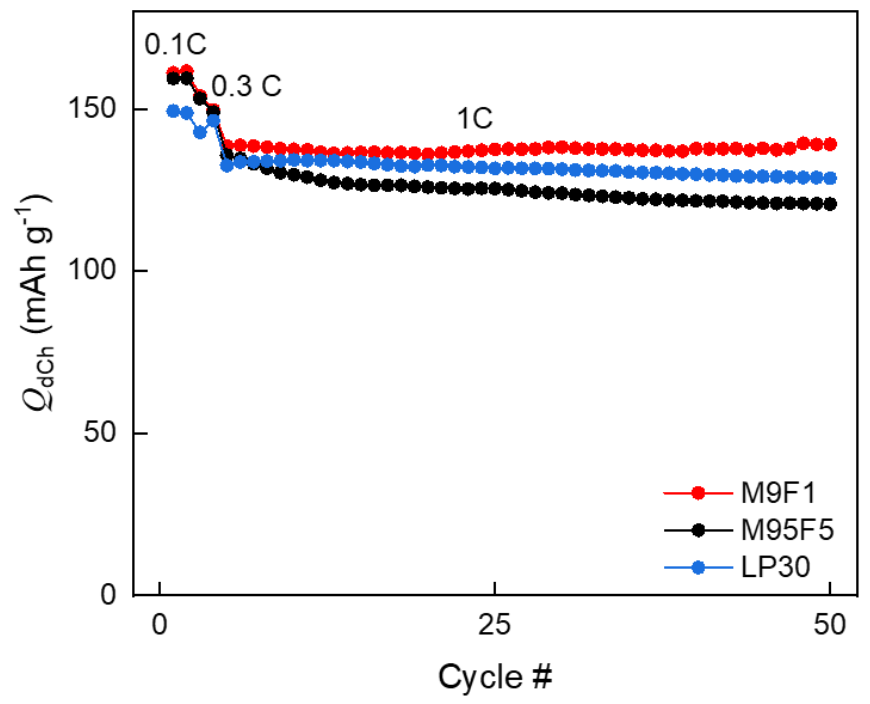

Figure S13. Cycling performance of cells at elevated temperature with different electrolytes (M95F5 represents electrolyte containing 95\% of MP and 5\% of FEC). The cycling test was conducted first at $0.1 \mathrm{C}$ for 2 cycles at room-temperature for activation, then the cells were transferred into the temperature chamber cycling at $0.3 \mathrm{C}$ for 2 cycles, $1 \mathrm{C}$ for the rest of cycles at $45^{\circ} \mathrm{C}$. 


\section{Reference:}

1. R. Petibon, J. Harlow, D.B. Le, J.R. Dahn, Electrochimica Acta, 2015, 154, 227-234. 